\title{
OPEN
}

\section{Publisher Correction: Study on the Visualization of Pigment in Haematococcus pluvialis by Raman Spectroscopy Technique}

Yongni Shao, Weimin Gu, Linjun Jiang, Yiming Zhu \& Aiping Gong

Correction to: Scientific Reports https://doi.org/10.1038/s41598-019-47208-2, published online 20 August 2019

Aiping Gong was omitted from the author list in the original version of this Article. As a result, Yongni Shao was incorrectly listed as the corresponding author. The correct corresponding author for this Article is Aiping Gong. Correspondence and request for materials should be addressed to gongap@sziit.edu.cn. This has been corrected in the PDF and HTML versions of the Article.

The Author Contributions section now reads:

"The work presented here was carried out in collaboration between all authors. YS conceived the idea and drafted the manuscript. WG, LJ co-worked on associated data collection, data analysis and carried out the experimental work. YZ have supported the instrument and technology. AG subsequently revised the paper and sponsored the publication of the paper."

\begin{abstract}
(c) Open Access This article is licensed under a Creative Commons Attribution 4.0 International (c) License, which permits use, sharing, adaptation, distribution and reproduction in any medium or format, as long as you give appropriate credit to the original author(s) and the source, provide a link to the Creative Commons license, and indicate if changes were made. The images or other third party material in this article are included in the article's Creative Commons license, unless indicated otherwise in a credit line to the material. If material is not included in the article's Creative Commons license and your intended use is not permitted by statutory regulation or exceeds the permitted use, you will need to obtain permission directly from the copyright holder. To view a copy of this license, visit http://creativecommons.org/licenses/by/4.0/.
\end{abstract}

(C) The Author(s) 2020 